\title{
Metode Koagulasi dan Elektrokoagulasi dengan Penambahan Hidrogen Peroksida pada Proses Pengolahan Limbah Cair Buangan Laundry
}

\section{Coagulation and Electrocoagulation Methods with The Addition of Hydrogen Peroxide on Laundry Waste Treatment}

\author{
Bambang Hari Prabowo ${ }^{a^{*}}$, Hendriyana ${ }^{a}$, Lulu Nurdini ${ }^{a}$, Mutiara C. Firdaus ${ }^{a}$, Tengku Leinaldy Pa .
}

${ }^{a}$ Jurusan Teknik Kimia, Fakultas Teknik Universitas Jend. Achmad Yani Cimahi Indonesia

\section{Artikel histori : \\ Diterima 25 April 2018 Diterima dalam revisi 17 Juni 2019 Diterima 26 Oktober 2019 Online 31 Oktober 2019}

\begin{abstract}
ABSTRAK: Industri rumah tangga yang membuang banyak limbah deterjen adalah usaha laundry (binatu). Surfaktan memiliki sifat sebagai penurun tegangan permukaan. Di dalam badan air bisa menyebabkan busa yang bisa menyebabkan rasa gatal. Sebagai limbah rumah tangga, limbah laundry ini biasanya dibuang langsung ke lingkungan tanpa pengolahan, yang jika dibiarkan, tentu saja akan berdampak buruk bagi lingkungan. Kandungan dalam limbah cucian seperti COD, BOD, TDS, pH, tingkat fosfat dan kekeruhan yang tidak memenuhi standar kualitas dapat menyebabkan lingkungan yang tercemar dan dapat mengganggu kesehatan masyarakat dan lingkungan. Dalam penelitian ini, dua metode pengolahan air diterapkan, yaitu koagulasi dan elektrokoagulasi dengan menambahkan $7 \mathrm{ml} 5 \%$ peroksida. Penelitian ini dilakukan dalam proses batch baik elektrokoagulasi dan koagulasi. Parameter yang ditinjau adalah COD, TSS, $\mathrm{pH}$, tingkat fosfat, $\mathrm{PO}_{4}{ }_{4}^{-}$dan kekeruhan. koagulasi menggunakan koagulan tawas (Aluminium sulfat). Variasi dari dua proses koagulasi adalah, untuk koagulasi, kecepatan pengadukan adalah $300 \mathrm{rpm}$ selama 10 menit dan dosis koagulan (500 ppm, 600 ppm, 700 ppm, 800 ppm, 900 ppm dan 900 ppm). Dalam elektrokoagulasi, waktu kontak divariasikan (15 menit, 20 menit, 25 menit, 30 menit). Hasil terbaik yang diperoleh adalah pengolahan air limbah menggunakan metode eletrokoagulasi dengan penurunan COD 76\%, BOD 83\%, kekeruhan 98\% dan fosfat 99,9\%.
\end{abstract}

Kata Kunci: Surfaktan, laundry; Elektrokoagulasi; Koagulasi; Aluminium sulfat; Fosfat

\begin{abstract}
Problems with laundry waste, especially in the content of surfactants in detergents. Surfactants have properties as surface tension reducers. In the body of water can cause foam that can mediate itching. As domestic waste, this laundry waste is generally disposed directly to the environment without any treatment, which if left unchecked, of course, will be bad for the environment. The content in laundry wastes such as COD, BOD, TDS, pH, phosphate level and turbidity that do not comply with quality standards can cause polluted environments and can disrupt public health and the environment. In this study, two water treatment methods were applied, namely coagulation and electrocoagulation by adding $7 \mathrm{ml}$ of $5 \%$ peroxide. This research was carried out in a batch process both electrocoagulation and coagulation. The parameters reviewed were COD, TSS, pH, phosphate level, PO4- and turbidity. Coagulation using alum coagulant (Aluminum sulfate). The variation of the two coagulation processes is, for coagulation, the stirring speed is $300 \mathrm{rpm}$ for 10 minutes and the coagulant dose (500 ppm, $600 \mathrm{ppm}, 700 \mathrm{ppm}, 800 \mathrm{ppm}$ and $900 \mathrm{ppm}$ ). In electrocoagulation contact times were varied ( 15 minutes, 20 minutes, 25 minutes, 30 minutes). The best results obtained were wastewater treatment using the Electrocoagulation method with a COD reduction of $76 \%$, BOD $83 \%$, turbidity $98 \%$ and phosphate $99.9 \%$.
\end{abstract}

Keywords: Surfactant; Laundry; Electrocoagulation; Coagulation; Aluminium sulfate; Phosphate.

\section{Pendahuluan}

*Corresponding Author:

Email: bambang.hari@lecture.unjani.ac.id
Laundry merupakan salah satu industri jasa pencucian pakaian dengan deterjen sebagai bahan pembantu yang saat ini mengalami perkembangan yang sangat pesat, terutama di provinsi Jawa Barat (Yuli Pratiwi, dkk 2012). 
Air buangan sisa deterjen yang di hasilkan dalam volume besar sangat berbahaya untuk kelestarian sungai dan tanah. Karena sifatnya yang kompleks, air limbah detergen/laundry sangat sukar untuk diolah. Kebutuhan air untuk industri laundry rata - rata $15 \mathrm{~L}$ untuk mencuci $1 \mathrm{~kg}$ cucian dan menghasilkan sekitar 400m3 limbah cair perhari (Ciabbati. dkk 2009). Pengolahan limbah cair hasil industri laundry sering menghadapi berbagai kesulitan diantaranya tingginya konsentrasi surfaktan, kadar zat organik dan anorganik yang terkandung dalam air buangan. Limbah cair laundry memiliki potensi sebagai pencemar lingkungan karena memliliki nilai COD, padatan tersuspensi (TSS), padatan terlarut (TDS), dan kadar fosfat yang sulit untuk didegradasi dalam badan air. Seperti penelitian yang telah dilakukan oleh Adysti Mareta dkk (2014) menunjukan bahwa nilai COD untuk air buangan laundry sebesar $986,98 \mathrm{mg} / \mathrm{L}$, nilai TSS sebesar $236 \mathrm{mg} / \mathrm{L}$, serta kadar fosfat sebesar 3,88 mg/L Nilai tersebut melebihi angka baku mutu air yang sesuai dengan Peraturan Menteri Lingkungan Hidup dan Kehutanan Republik Indonesia Nomor P.68/Menlhk/Setjen/Kum.1/8/2016 dan Peraturan Pemerintah Nomor 82 Tahun 2001.

Atas dasar permasalahan di atas maka perlu adanya metoda alternatif yang dapat mereduksi tingkat bahaya yang ditimbulkan oleh limbah laundry. Kebanyakan metoda yang umum diterapkan untuk mengolah air buangan sisa deterjen/laundry merupakan metoda konvensional seperti koagulasi dan flokulasi, sedimentasi dan filtrasi, atau kombinasi dari proses tersebut (Subriyer Nasir, 2013). Sedangkan metode alternatif untuk mengolah air limbah laundry yaitu melalui proses elektrokoagulasi. Tujuan dari penelitian ini adalah mengkaji kemampuan $\mathrm{H}_{2} \mathrm{O}_{2}$ terhadap kinerja koagulasi dan elektrokoagulasi.

\section{Metode Penelitian}

Pada penelitian ini dilakukan tiga tahapan utama yaitu tahapan percobaan pendahuluan, proses penelitian dan analisis pengujian hasil akhir.

Pada percoban pendahuluan dilakukan dengan menyiapkan reaktor untuk proses koagulasi dan elektrokoagulasi. Untuk reaktor yang digunakan pada proses koagulasi menggunakan reaktor dengan ukuran $1 \mathrm{~L}$ yang di pasangi motor pengaduk sementara untuk reaktor proses elektrokoagulasi menggunakan reaktor berukuran 5 L dengan di pasangi elektroda yang berjarak $5 \mathrm{~cm}$ antar elektrodanya. Lalu melakukan percobaan pada berbagai macam variasi dimana didapatkan hasil yang optimum yang akan digunakan untuk penelitian yang akan dilakukan.

Hasil yang digunakan untuk penelitian yang akan dilakukan. Pada proses koagulasi digunakan variasi berat koagulan yang digunakan yaitu mulai dari 0,5 gram, 0,6 gram, 0,7 gram, 0,8 gram dan 0,9 gram dengan lama pengadukan 10 menit dengan penambahan larutan $\mathrm{H}_{2} \mathrm{O}_{2}$ $5 \%$ sebanyak $7 \mathrm{ml}$. Sementara untuk proses elektrokoagulasi dengan menggunakan elektroda
Aluminium (3 Anoda 3 Katoda) digunakan variasi waktu operasi selama 15 menit, 20 menit, 25 menit dan 30 menit

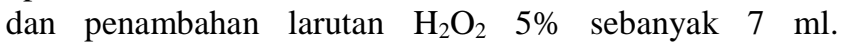
Parameter yang di uji pada percobaan pendahuluan ini adalah TDS, Turbidity, $\mathrm{pH}$ dan Konduktivitas

Tabel 1. Baku Mutu Air Limbah Industri Sabun dan

\begin{tabular}{|c|c|c|c|}
\hline \multicolumn{4}{|c|}{ Detergen } \\
\hline \multirow[t]{2}{*}{ Parameter } & \multirow[t]{2}{*}{$\begin{array}{c}\text { Kadar } \\
\text { Maksimum } \\
(\mathrm{mg} / \mathrm{L})\end{array}$} & \multicolumn{2}{|c|}{$\begin{array}{c}\text { Beban Pencemar } \\
\text { Maksimum } \\
\text { (Kg/ton Produk) }\end{array}$} \\
\hline & & Sabun & Detergen \\
\hline $\mathrm{BOD}_{5}$ & 75 & 0.6 & 0.075 \\
\hline COD & 180 & 1.44 & 0.180 \\
\hline TDS & 2000 & 0.48 & 0.060 \\
\hline Phospat $\mathrm{PO}_{4}$ & 2 & 0.016 & 0.002 \\
\hline $\mathrm{pH}$ & & $6.0-9.0$ & \\
\hline Debit & & $8 \mathrm{~m}^{3} /$ ton & $1 \mathrm{~m}^{3} /$ ton \\
\hline Maksimum & & produk & produk \\
\hline
\end{tabular}

Sumber: PerMen KLH-RI Nomor 5 tahun 2014

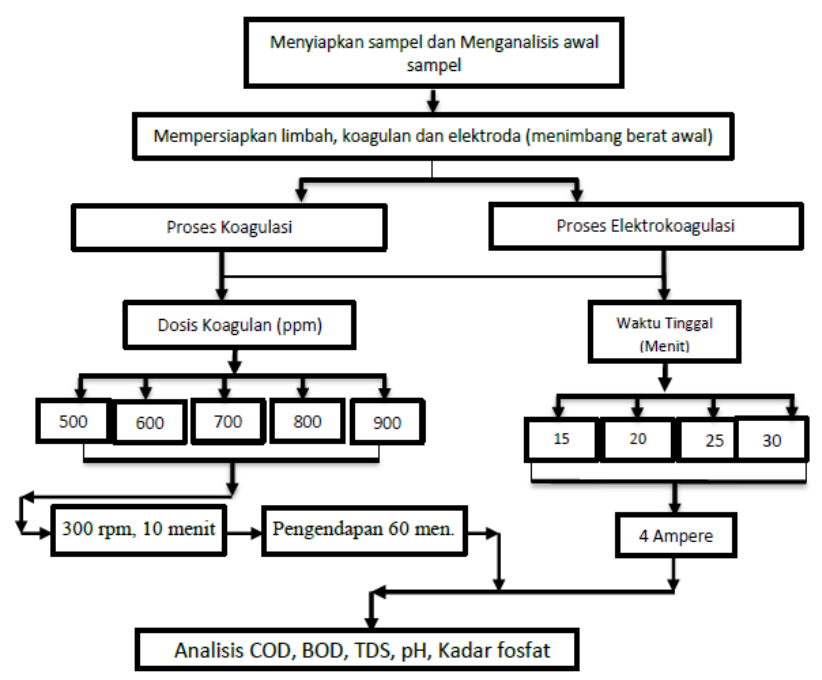

Gambar 1. Diagram Alir Penelitian Koagulasi dan Elektrokoagulasi

\section{Hasil dan Pembahasan}

Dengan limbah cair yang sama dilakukan perlakuan yang berbeda yang pertama menggunakan metode koagulasi dengan koagulan alumunium sulfate $(\mathrm{A} 12(\mathrm{SO} 4) 3)$ atau yang sering kita ketahui sebagai tawas dan metode elektrokoagulasi dengan menggunakan elektroda Aluminium (3 Anoda 3 Katoda). Pada kedua metode tersebut ditambahkan larutan $\mathrm{H} 2 \mathrm{O} 2$ dengan konsentrasi 5\% sebanyak $7 \mathrm{ml}$ untuk membantu proses oksidasi. $\mathrm{H} 2 \mathrm{O} 2$ merupakan oksidator kuat yang ramah lingkungan dibandingkan dengan oksidator lainnya, mudah didapat dan ekonomis.

\subsection{Hasil Analisis}

Dari penelitian yang telah dilakukan didapat hasil analisa pada kondisi optimum seperti pada tabel dibawah ini: 
Eksergi, Vol 16, No. 2. 2019

ISSN: $1410-394 \mathrm{X}$

Tabel 2. Hasil Analisa Koagulasi dan Elektrokoagulasi

\begin{tabular}{ccccccc}
\hline Metode & pH & $\begin{array}{c}\text { TDS } \\
(\mathbf{p p m})\end{array}$ & $\begin{array}{c}\text { BOD } \\
(\mathbf{p p m})\end{array}$ & $\begin{array}{c}\text { COD } \\
(\mathbf{p p m})\end{array}$ & $\begin{array}{c}\text { Turbidity } \\
(\mathbf{p p m})\end{array}$ & $\begin{array}{c}\text { Fosfat } \\
(\mathbf{p p m})\end{array}$ \\
\hline $\begin{array}{c}\text { Sampel } \\
\text { awal }\end{array}$ & 8 & 533 & 134,37 & 649,51 & 133 & 18,7 \\
\hline Koagulasi & 6 & 793 & 24.72 & 217,87 & 16,9 & 0,928 \\
\hline Elektro & & \multirow{2}{*}{932} & 23,17 & 155 & 2,13 & 0,0094 \\
koagulasi & & & & & & \\
\hline
\end{tabular}

\subsection{Proses Koagulasi}

Pada gambar 2 dapat dilihat bahwa nilai BOD5 dalam sampel mengalami menurun terhadap bertambahnya konsentrasi tawas, dimana pada sampel awal nilai BOD5 yang sebesar $134,37 \mathrm{ppm}$, setelah di lakukan pengolahan nilai BOD5 terendah di dapat pada variasi konsentrasi koagulan sebesar 0,9 gram ( $900 \mathrm{ppm}$ ) dimana nilai BOD yang di dapat sebesar 24,72 ppm. Hasil ini cukup baik karena telah memenuhi standar baku mutu air limbah laundry yaitu maksimum 75 ppm.

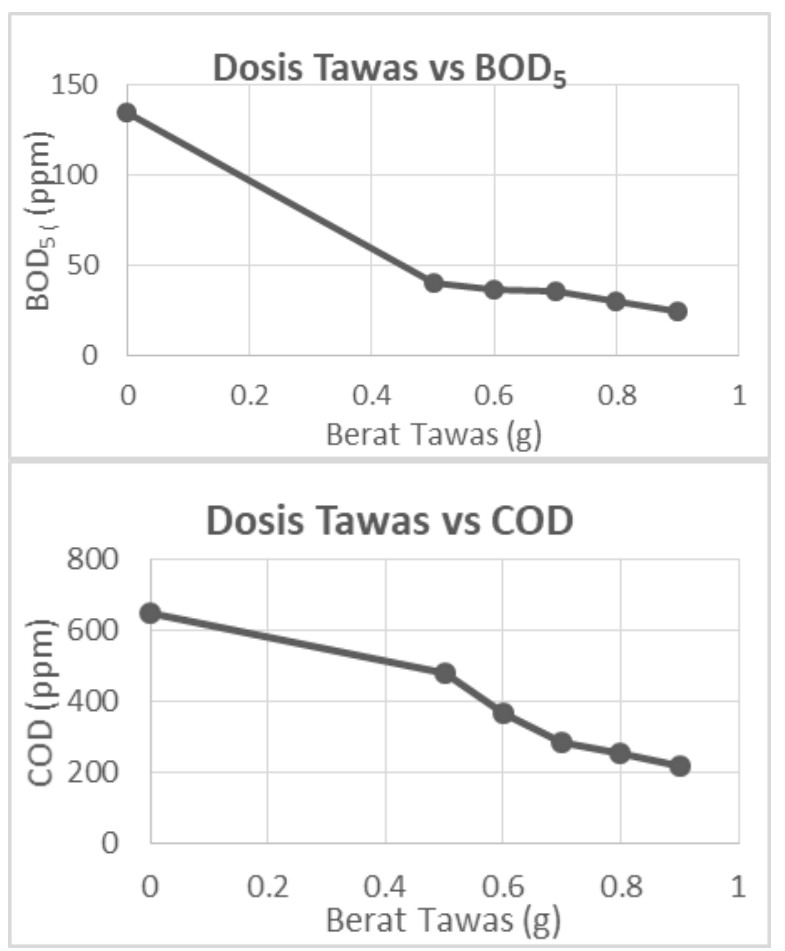

Gambar 2. Pengaruh Dosis Koagulan Tawas terhadap Perubahan Kadar BOD5 dan COD dalam Sampel

COD atau Chemical Oxygen Demand merupakan jumlah oksigen yang dibutuhkan untuk proses oksidasi limbah cair agar dapat teroksidasi oleh reaksi kimia (Agustira, 2013). Pada penelitian ini kadar COD dalam sampel berkurang terhadap banyaknya jumlah koagulan yang di tambahkan. Semakin besar jumlah koagulan di tambahkan pada reaktor maka kadar COD dalam larutan semakin berkurang. Dalam hal ini pada penambahkan koagulan sebesar 0,9 gram (900 ppm) didapat hasil yang maksimum sebesar 217,87 ppm dengan nilai COD pada sampel awal sebesar 649,51 ppm. Hasil yang kami dapat belum memenuhi karakteristik baku mutu air limbah laundry yaitu 180 ppm di karenakan sampel laundry yang kami gunakan memiliki kandungan bahan kimia yang cukup tinggi.

Senyawa fosfat terkandung pada detergent sebagai builder yaitu sebagai pencegah kotoran untuk menempel kembali pada bahan yang dicuci namun senyawa fosfat dapat berbahaya jika dibiarkan begitu saja di buang ke lingkungan (Hudori,2008). Pada penelitian ini senyawa fosfat yang terkandung dalam fosfat harus dikurangi kadarnya dapat dilihat pada gambar 1.2 diatas bahwa kadar fosfat yang terkandung di dalam sampel berkurang seiring dengan besarnya penambahan koagulan dimana di dapat hasil pada penambahan koagulan sebesar 0,9 gram (900 ppm) di dapat hasil 0,9281 ppm. Hasil ini dinyatakan baik karena memenuhi syarat baku mutu air limbah laundry yang dibolehkan memiliki nilai kadar maksimal fosfat 2 ppm.

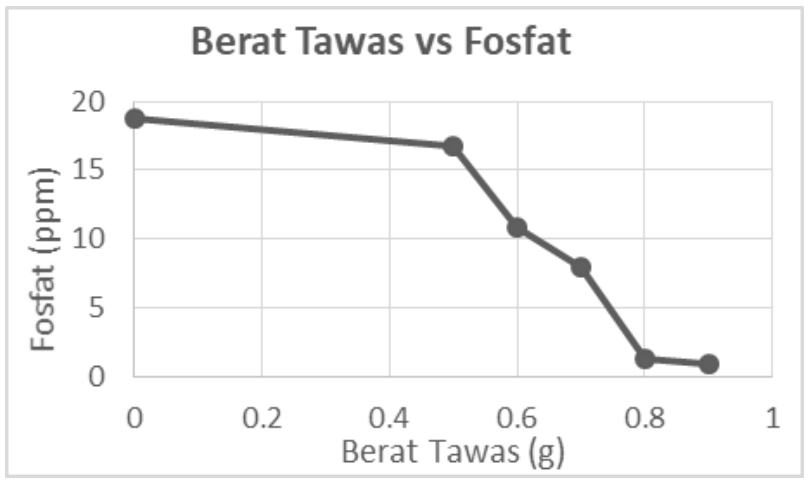

(a)

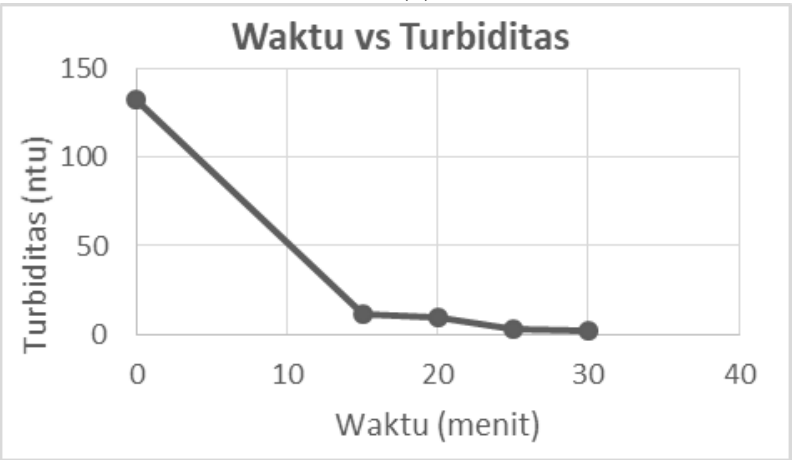

(b)

Gambar 3 (a) pengaruh berat koagulan tawas yang digunakan terhadap kadar fosfat dalam air sampel dan (b) pengaruh waktu elektrokoagulasi terhadap penurunan kekeruhan (turbidity). 


\subsection{Proses Elektrokoagulasi}

Pada hasil penelitian dari turbiditas, menunjukan semakin lama proses elektrokoagulasi maka akan mengalami penurunan nilai turbiditas atau kekeruhannya gambar 3 (b). Pada sampel awal nilai turbiditas 133 ntu, dan semakin menurun seiring semakin lamanya proses elektrokoagulasi dan maksimumnya terjadi pada proses elektrokoagulasi dengan waktu 30 menit dengan nilai turbiditas menjadi $2.13 \mathrm{ntu}$, dengan persentase penurunan sebesar 98\%. Hal ini disebabkan karena proses elektrokoagulasi berlangsung reaksi oksidasi dan reduksi, dengan penambahan $\mathrm{H} 2 \mathrm{O} 2$ reduksi terhadap polutan meningkat berakibat partikulat terangkat dan terendapkan air menjadi lebih jernih.

Sampel merupakan limbah cair laundry yang diambil langsung dari salah satu usaha laundry di daerah cimahi dan langsung diolah dengan metode elektrokoagulasi. Dalam penelitian ini kami menggunakan variasi waktu dengan arus tetap yaitu 4 ampere dengan penggunaan 3 katoda dan 3 anoda.

Berdasarkan hasil percobaan pada elektrokoagulasi, nilai COD dan BOD semakin turun nilainya seiring dengan lamanya waktu proses elektrokoagulasi. Sampel awal menunjukan nilai COD sebesar 649.51 ppm dan BOD5 sebesar 134.37 ppm, setelah dilakukan proses elektrokoagulasi nilai COD dan BOD turun cukup tinggi dari sampel awal. Pada elektrokoagulasi 15 menit nilai COD turun menjadi 291.67 ppm dan BOD5 turun menjadi 42.32 ppm, dengan persentase penurunan pada COD sebesar $55 \%$ dan BOD5 sebesar $68 \%$. Nilai COD dan BOD5 mengalami penurunan masing-masing mencapai $82 \%$ dan $76 \%$ setelah proses elektrokoagulasi selama 30 menit. Atau kandungan COD menurun manjadi 155 ppm dan BOD 23,17 ppm. Reaksi reduksi dan oksidasi pada elektrokoagulasi, ion-ion $\mathrm{Al}+3$ dari elektroda anoda $\mathrm{Al}$ yang dapat mengikat PO4- menjadi koagulan $\mathrm{Al3PO} 4$ yang mengendap. Sedangkan hasil reduksi menghasilkan gas $\mathrm{H} 2$ dari $\mathrm{H}+$, yang mengkoagulasikan polutan melayang terapung ke atas permukaan, dan mengikat PO4- menjadi endapan $\mathrm{H} 2 \mathrm{PO} 4$

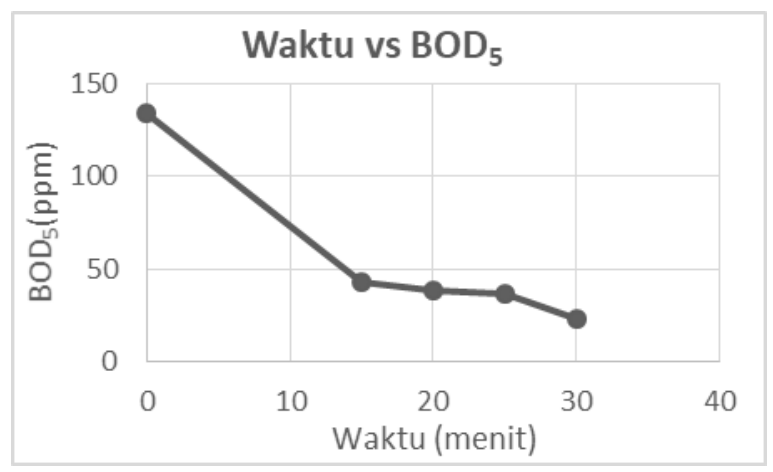

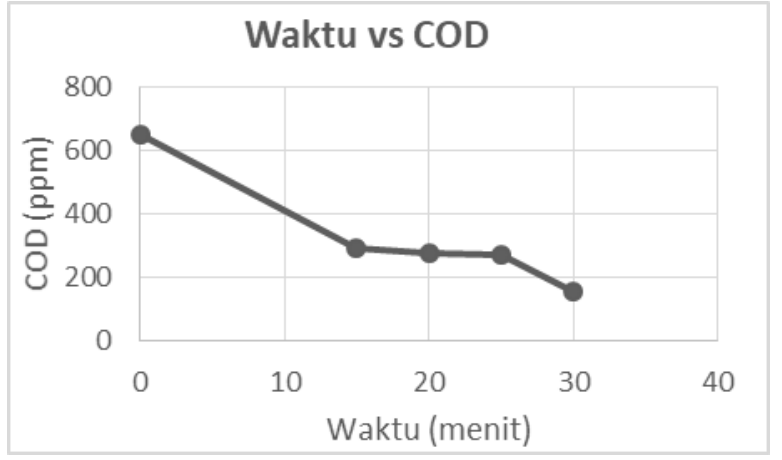

Gambar 4. Pengaruh Waktu Elektrokoagulasi terhadap Penurunan Kadar BOD dan COD

Pada gambar 5 menunjukkan kadungan phosfat dapat tereduksi maksimal pada proses elektrokoagulasi selama 30 menit, hasil analisis sebelum elektrokoagulasi 18,7 ppm setelah elektrokoagulasi menjadi 0,0094 ppm. . Hasil ini sangat baik karena memenuhi syarat baku air mutu limbah untuk kadar fosfat sebesar 2 ppm. Walaupun demikian ada efek samping dari proses ini, terutama meningkatnya $\mathrm{pH}$ sebagai akibat dari produksi reduksi berupa $\mathrm{OH}-$ dan hasil oksidasi yaitu $\mathrm{Al} 3+$.

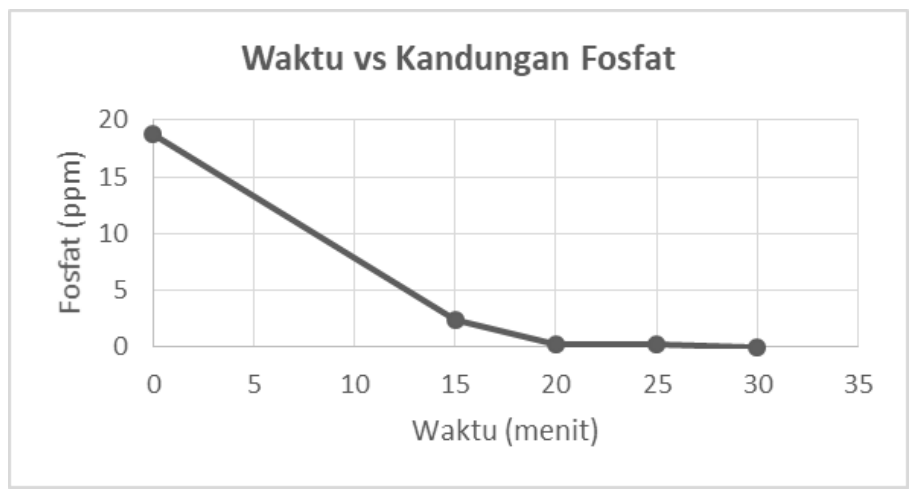

Gambar 5. Pengaruh Waktu ELektrokoagulasi terhadap kadar fosdat

\subsection{Perbandingan Metode Elektrokoagulasi}

Dari analisa yang telah di lakukan didapat hasil dari kedua proses dengan persentasi penurunan polutan seperti gambar 6. Dari Gambar 6 dapat kita lihat bahwa penurunan terbesar untuk metode elektrokoagulasi dengan waktu operasi selama 30 menit didapat hasil BOD $_{5}$ sebesar 83\%, COD sebesar $76 \%$, kadar fosfat sebesar $99,95 \%$ dan tubiditas sebesar $98 \%$. Sedangkan metode koagulasi pada penggunaan koagulan dengan berat tawas (koagulan) sebanyak 0,9 gram (900 ppm) maksimum, persentase penurunan pencemar sangat tinggi yaitu untuk penurunan $\mathrm{BOD}_{5}$ sebesar $82 \%$, COD sebesar $66 \%$, kadar fosfat sebesar $95 \%$ dan tubiditas sebesar $87 \%$. 


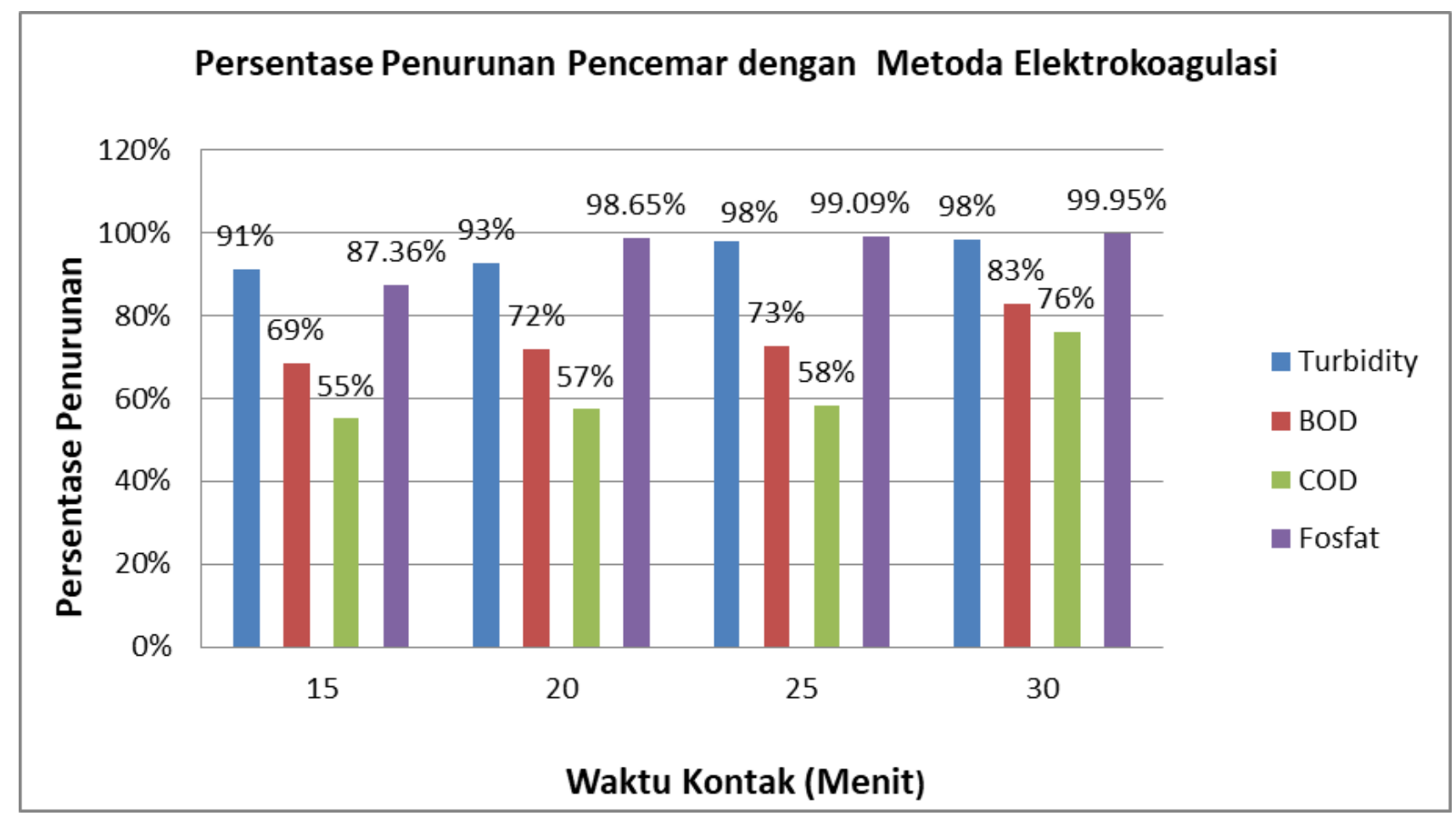

Gambar 6. Penurunan (\%) kadar pencemar Metode Elektrokoagulasi terhadap Konsentrasi Koagulan

\section{Kesimpulan}

Dari penelitian yang telah kami lakukan dapat disimpulkan bahwa kedua metode baik koagulasi maupun metode elektrokoagulasi sangat baik digunakan untuk mengolah air limbah khususnya limbah cair laundry. Metode Elektrokoagulasi memiliki hasil yang lebih baik dibandingkan metode Koagulasi.

Metode koagulasi dapat menurunkan nilai BOD sebesar $82 \%$ dan COD $66 \%$ pada penggunaan tawas sebesar 0,9 gram ( 900 ppm). Sedangnkan untuk metode Elektokoagulasi dapat menurunkan nilai BOD sebesar $83 \%$ dan COD sebesar $76 \%$.

Pada penurunan kadar fosfat untuk metoda koagulasi menurunkan kadar fosfat sebesar $95 \%$ dan untuk metoda elektrokoagulasi menurunkan kadar fosfat sebesar 99,9\%.

\section{Ucapan Terima kasih (Acknowledgments)}

Ucapan Terimakasih kepada LPPM - UNJANI yang telah membantu sepenuhnya pendanaan, sehingga penelitian ini dapat terlaksana dengan baik.

\section{Daftar Pustaka (References)}

Noh, D.O., Kim, S.H. \& Gilliland, S.E., 1997, Incorporation of cholesterol into the cellular membrane of Lactobacillu acidphilus, Jurnal Exergy, Vol.2 No.1, Juni: 07-13.
Agustira R., Lubis K.S. dan Jamilah. 2013. Kajian Karakteristik Kimia Air, Fisika Air dan Debit Sungai pada KSawasan DAS Padang Akibat Pembuangan Limbah Tapioka. Jurnal Online Agroteknologi Vol. 1 No. 3. Medan: USU.

Budi, Sudi Setyo. 2006, Penurunan Fosfat Dengan Penambahan Kapur (Lime), Tawas, Dan Filtrasi Zeolit Pada Limbah Cair (Studi Kasus RS Bethesda Yogyakarta). Program Magister Ilmu Lingkungan Program Pascasarjana Universitas Diponegoro, Semarang.

Ciabatti, I., Cesaro F., Farali L., Fatarella E., Tognotti F.,. 2009, Demonstration of treatment system fot purification and reuse of laundry waste water. 1-2.

Furqon, Kamilul,. 2008, Daur Ulang Air Limbah Usaha Pencucian Kendaraan Bermotor Dengan Menggunakan Elektrokoagulasi. Universitas Mulawarman Samarinda.

Holt,P. K., Geoffrey, W. Barton, Mary, W., Cynthia A. Mitchell,. 2002, A Quantitative Comparison Between Chemical dosing and Electrocoagulation. Department of Chemical Engineering. Univesity of Sydney.

Holt, P. K., Geoffrey W. Barton, Cynthia A. Mitchell,. The future for electrocoagulation as a localised water treatment technology. Department of Chemical Engineering. Univesity of Sydney. 
Hudori, 2008, Pengolahan Air Limbah Laundry Dengan Menggunakan Elektrokoagulasi. Institut Teknologi Bandung.

LH, K., 2014, PERATURAN MENTERI LINGKUNGAN HIDUP REPUBLIK INDONESIA NOMOR 5 TAHUN 2014 TENTANG BAKU MUTU AIR LIMBAH. 1-85.

Leyster, Theresia G. 2016, Pengaruh Dosis H2O2 Terhadap Penurunan Sianida Pada Effluen CIC (Carbon in Column) Di PT Cibaliung Sumberdaya. Cimahi., Universitas Jenderal Achmad Yani.

Mollah, M. A., \& Schennach R, J. R. 2004, Electrocoagulation (EC) Science and Applications. Journal of Hazardous Material .
Pratiwi, Y., Sunarsih Sri, Windi F. Winda. 2012, Uji Toksisitas Limbah Cair Laundry Sebelum Dan Sesudah Diolah Dengan Tawas Dan Karbon Aktif Terhadap Bioindikator (Cyprnuscarpio L). Prosiding seminar nasiona aplikasi dan sains (SNAST).

Prihessy, Y., 1999, Penurunan Kadar Deterjen limbah Laundry dengan Cara Adsorpsi menggunakan Karbon Aktif pada Merpati Laundry Mancasan Lor Depok Sleman., Skripsi, Teknik Lingkungan, Sekolah Tinggi Teknik Lingkungan 